\title{
Linfoma difuso de grandes células B em cavidade oral
}

\author{
Diffuse large B-cell lymphoma in the oral cavity
}

\author{
LUCAS DE OLIVEIRA TEIXEIRA ${ }^{1}$ \\ MURIEL BOTINI VIEIRA \\ NANCY ALFIERI NUNES ${ }^{2}$ \\ GIOVANI FURLANETTO ${ }^{3}$ \\ ANA LUCIA CONELIAN GENTILI ${ }^{4}$
}

\begin{abstract}
RESUMO
IO linfoma difuso de grandes células B é responsável por $68 \%$ dos casos de linfoma não Hodgkin na cavidade oral, podendo acometer linfonodos, orofaringe, vestíbulo bucal, região posterior de palato duro e gengivas. Objetivo: $O$ objetivo deste trabalho é relatar o caso clínico de uma paciente que compareceu ao Serviço Estomatológico com queixa de trismo e dor na cavidade bucal durante duas semanas. Caso Clínico: Paciente do sexo feminino, 61 anos de idade, leucoderma, apresentou-se com assimetria facial do lado esquerdo e massa nodular ulcerada na região retromolar, mucosa jugal e palato mole do lado esquerdo, com necrose superficial e sintomatologia dolorosa local, acompanhando emagrecimento, quadro instalado após avulsão do dente 27. No soalho de boca posterior havia um nódulo de aproximadamente 2 $\mathrm{cm}$, doloroso, cuja hipótese diagnóstica inicial foi de carcinoma espinocelular ou fibrossarcoma. Apresentou linfadenopatia de caráter neoplásico. Foi submetida à punção aspirativa por agulha fina de linfonodo, que demonstrou presença de material necrótico e linfócitos maduros; e à biópsia incisional que, após avaliação histopatológica, demonstrou linfoma difuso de grandes células B. Conclusão: A imunoistoquímica indicou positividade para CD 20 e fenótipo para linfócitos B pelo Ki 67 , com $80 \%$ de células neoplásicas. Após o diagnóstico, a paciente foi encaminhada para tratamento oncológico, sendo submetida a oito sessões de quimioterapia, seguido de radioterapia, com excelente resultado. É de suma importância a avaliação sistemática pelo cirurgião-dentista devido à heterogeneidade clínica do linfoma difuso de grandes células $\mathrm{B}$ e a importância do diagnóstico precoce visando uma maior taxa de sobrevida do paciente.
\end{abstract}

Palavras-chave: Linfoma. Linfoma não Hodgkin. Linfoma difuso de grandes células B. Cavidade oral.

\section{ABSTRACT}

Diffuse large B-cell lymphoma is responsible for $68 \%$ of cases of non-Hodgkin's lymphoma in the oral cavity, affecting lymph nodes, oropharynx, buccal vestibule, posterior hard palate and gums. Objetive:The obective of this study is to report a case of a patient who attended a Stomatological Service complaining of trismus and oral cavity pain along for two weeks. Case Report: A 61-year-old female patient arrived at the stomatological service presenting left facial asymmetry and an ulcerated nodular mass in the retromolar region, jugal mucosa and left soft palate and superficial necrosis also presenting local painful symptomatology, accompanying weight loss, after avulsion of tooth 27 . On the floor of the mouth there was a painful nodule of approximately $2 \mathrm{~cm}$ whose initial diagnostic hypothesis was squamous cell carcinoma or fibrosarcoma. She presented neoplastic lymphadenopathy. She underwent fine-needle aspiration lymph node puncture which showed the presence of necrotic material and mature lymphocytes; the incisional biopsy, after histopathological evaluation, showed diffuse large B cell lymphoma. The immunohistochemistry indicated CD 20 positivity and B lymphocyte phenotype by Ki 67 with $80 \%$ of neoplastic cells. Conclusion: After diagnosis, the patient was referred for cancer treatment and underwent eight chemotherapy sessions, followed by radiotherapy, with excellent results. Systematic evaluation by dentists of patients with malignant lesions aims at early diagnosis and higher patient survival rate.

Keywords: Lymphoma. Non-Hodgkin's Lymphoma. Diffuse large B-cell lymphoma. Oral cavity.

\footnotetext{
${ }^{1}$ Cirurgião-dentista pela Faculdade de Odontologia de Lins da Universidade Metodista de Piracicaba.

${ }^{2}$ Doutora-Docente da Faculdade de Odontologia de Lins - Departamento de Diagnóstico Bucal - Universidade Metodista de Piracicaba.

${ }^{3}$ Cirurgião Bucomaxilofacial - Responsável Técnico - Departamento de Odontologia do Hospital Amaral Carvalho - Jaú-SP.

${ }^{4}$ Ms Patologista - Laboratório de Citologia e Histopatologia de Lins-SP.
} 


\section{INTRODUÇÃO}

Os linfomas podem ser divididos em linfomas de Hodgkin e linfomas não Hodgkin (LNH). Os LNH são responsáveis por $60 \%$ dos casos de linfomas e são classificados como: linfoma de células B (mais comuns) ou linfoma de células T. ${ }^{1}$ Segundo o projeto da Agência Internacional de Pesquisa sobre Câncer (AIPC) - GLOBOCAN, estima-se que ocorreram 509.590 novos casos de LNH e 248.724 mortes no mundo, em 2018. ${ }^{2}$ No Brasil, por razões desconhecidas, o número de casos dobrou nos últimos 25 anos, sobretudo entre indivíduos com mais de 60 anos de idade. ${ }^{3}$

$O$ linfoma difuso de grandes células B (LDGCB) é a variante mais comum em meio a todos os subtipos de $\mathrm{LNH}$ que acometem o sistema estomatognático, representando uma neoplasia agressiva correspondente a $30 \%-35 \%$ do $\mathrm{LNH}$ adulto em todo o mundo. ${ }^{4} \mathrm{O}$ LDGCB representa $68 \%$ dos casos de $\mathrm{LNH}$ da cavidade oral e a idade média prevalente, nessa região, é de 66 anos. Sendo o sexo feminino o mais afetado, seguindo uma proporção de 2: 1 em relação ao masculino. ${ }^{5}$

Cerca de um terço dos $\mathrm{LNH}$ atinge estruturas extranodais. ${ }^{1}$ Logo, apesar de comumente se apresentarem como linfoadenopatias localizadas ou disseminadas, a lesão primária pode ocorrer em outros sítios como orofaringe, pele, trato gastrointestinal e medula óssea. ${ }^{5}$ Assim, o LDGCB possui alta heterogeneidade clínica/patológica, o que ainda contribui para a sua etiologia continuar incerta. ${ }^{4,6}$

A sintomatologia do LDGCB geralmente surge com perda de peso, febre e sudorese noturna, como em outros subtipos do LNH. Na cavidade bucal, podem aparecer lesões como tumores disseminados com envolvimento de vestíbulo oral, região posterior do palato duro e gengivas. ${ }^{5}$

Apesar de a maioria dos pacientes não apresentar fatores de risco, certos casos exibem uma evolução de alto grau de um linfoma indolente ou podem surgir em quadros de uma imunodeficiência, como positividade para o vírus Epstein-Barr. ${ }^{4}$

O diagnóstico é complexo e deve seguir uma análise histopatológica, imuno-histoquímica e de exames imaginológicos, como a ressonância magnética, sendo imprescindíveis para classificar o tipo específico de linfoma. O LDGCB possui grandes variações em suas características moleculares, necessitando de terapias específicas para cada caso. Tudo isso faz que a precisão do diagnóstico seja essencial para a eficácia do tratamento. ${ }^{4}$

A principal modalidade terapêutica utilizada para esse tipo de linfoma é a quimioterapia à base de antraciclina (CHOP) ou em associação ao rituximabe (R-CHOP). Pode alcançar a remissão completa em $35 \%-40 \%$ dos pacientes. Quando o tumor atinge estruturas nobres em massa, a ressecção da lesão inteira não é indicada, mas parte dela deve ser removida para diagnóstico diferencial. Além disso, radioterapia e cirurgia entram como terapias coadjuvantes a dependerem da especificidade do LDGCB..$^{5,7}$ Os pacientes atingem uma taxa inicial de resposta positiva ao tratamento de $75-80 \%$. Porém, $40 \%$ têm recidiva da doença ou não respondem à terapia primária. ${ }^{6}$

Este trabalho tem por objetivo relatar o caso clínico de uma paciente que compareceu a um serviço estomatológico na cidade de Lins-SP e, após a realização de todos os exames, apresentou diagnóstico correspondente a linfoma difuso de grandes células B na cavidade oral.

\section{ReLATO de CAso clínico}

Por intermédio da assinatura do Termo de Consentimento Livre e Esclarecido, em respeito à Resolução 466/2012, do Conselho Nacional do Ministério da Saúde, a paciente autorizou o uso de dados clínicos, fotografias e exames laboratoriais.

Paciente do sexo feminino, com 61 anos de idade, leucoderma, empresária, casada, compareceu ao Serviço Estomatológico com queixa de edema e algia lingual, com histórico de duas semanas, após avulsão do dente 27 que estava com mobilidade. Queixou-se de aumento de volume significativo na língua, ruído em articulação temporomandibular esquerda e perda de peso nas últimas semanas e foi submetida a tratamento com anti-inflamatório. A mesma relatou ser portadora de hipertensão arterial e depressão fazendo uso de medicação contínua; alergia a produtos químicos, metal, frutos do mar e amendoim. No histórico familiar, referiu hipertensão arterial, diabete mellitus e tuberculose.

Ao exame físico apresentou-se normolínea, com ligeiro subpeso, assimetria facial e parotídea do lado esquerdo (Figura $1 \mathrm{~A}$ ) e quadro hipertensivo significante $(210 \times 115 \mathrm{mmHg})$. No exame intrabucal, demonstrou limitação de abertura bucal severa e úlcera envolvendo toda a região retromolar, 
mucosa jugal e palato mole do lado esquerdo, com área de massa nodular acompanhando a ulceração e necrose superficial. No soalho de boca posterior esquerdo havia um nódulo de aproximadamente $2 \mathrm{~cm}$, doloroso (Figuras 1B, 1C e 1D). Havia também halitose intensa. Apresentou linfoadenopatia submandibular, cervical profunda superior e parotídea do lado esquerdo, de caráter neoplásico, com infiltração dos tecidos subjacentes e adjacentes aos linfonodos. Detectou-se alteração da região submandibular esquerda, com aumento de volume e endurecimento da área. Mostrou também uma radiografia panorâmica (Figura 2). Tendo em vista a dificuldade de abertura bucal e quadro de hipertensão grave, a paciente foi encaminhada ao cardiologista para controle arterial e retorno para biópsia, com solicitação de tomografia computadorizada. Passaram-se 20 dias e a mesma compareceu para biópsia ainda com o quadro de hipertensão (191 X $98 \mathrm{mmHg}$ ), o que impossibilitou a realização do referido exame complementar, logo, foi encaminhada ao oncologista. A hipótese diagnóstica inicial foi de carcinoma espinocelular ou fibrossarcoma.

O oncologista solicitou uma ressonância magnética do pescoço e realizou uma punção aspirativa com agulha fina (PAAF) de linfonodo da região. O resultado demonstrou material necrótico extenso, com raras células anaplásicas isoladas ou aglomeradas, além de linfócitos maduros. As células exibiam núcleos ovoides com cromatina grumosa e nucléolos proeminentes. O resultado foi de positividade para malignidade, com raras células anaplásicas indiferenciadas e necrose tumoral. Inconclusivo, porém, para determinar o tipo de malignidade.
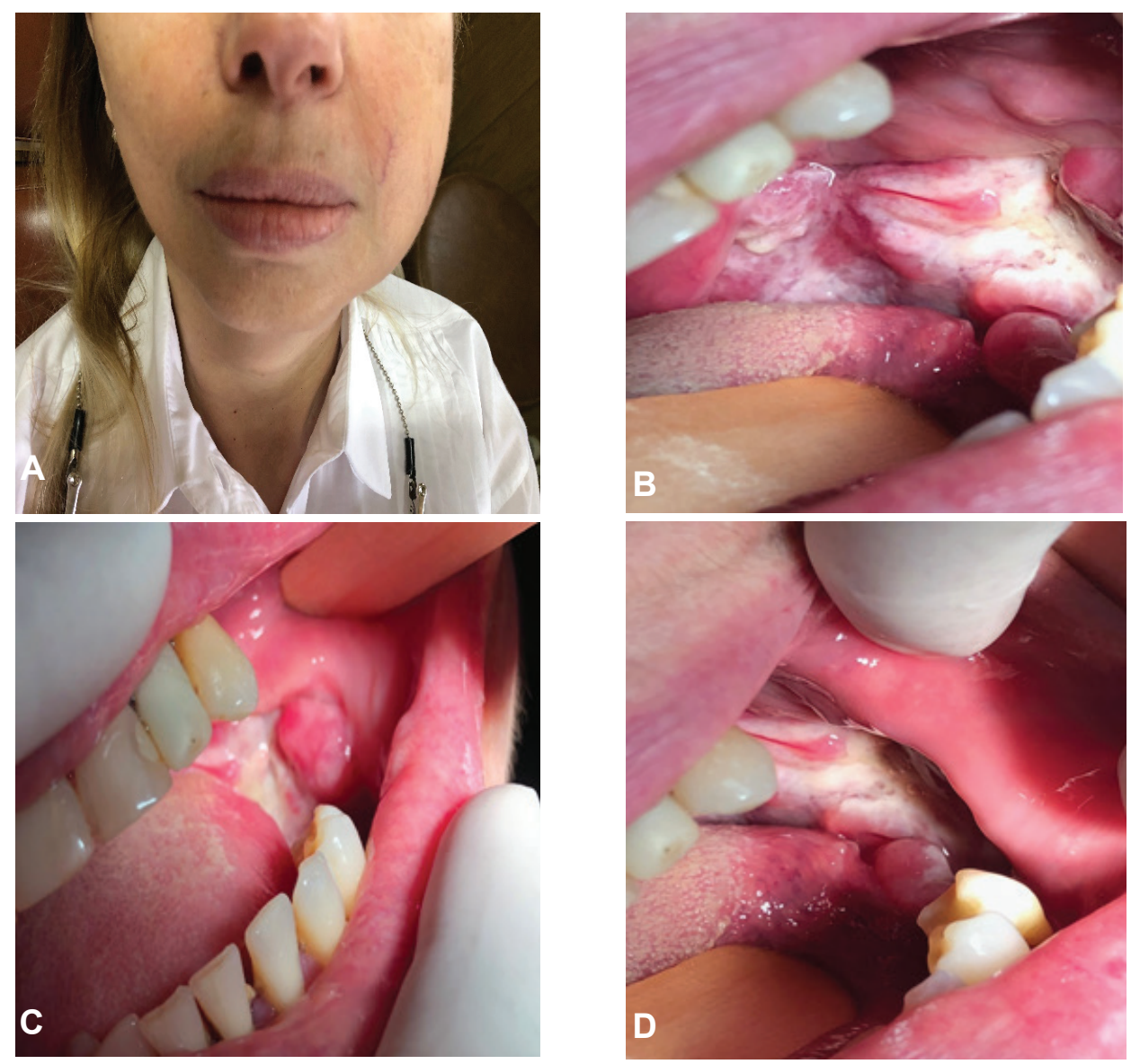

Figura 1 - Aspectos clínicos. 1A-Assimetria facial parotídea, mandibular e submandibular esquerda. 1B - Massa nodular na mucosa jugal e palato mole com ulceração e necrose superficial. 1C - Nódulo de consistência firme na mucosa jugal esquerda. 1D - Área de ulceração e necrose no soalho bucal. 


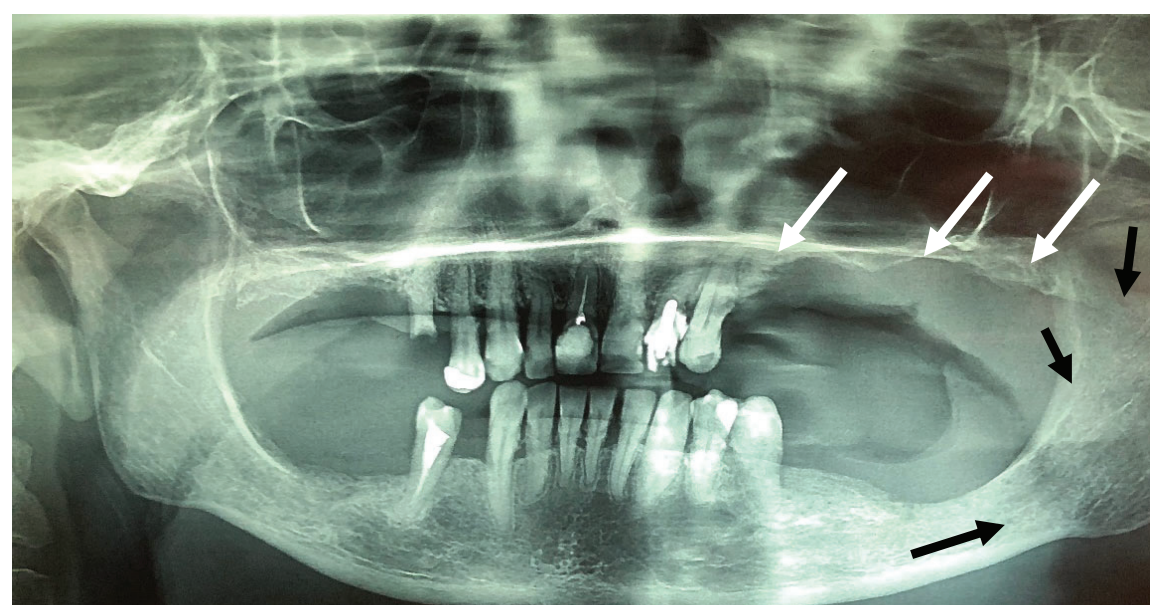

Figura 2 - Radiografia panorâmica inicial demonstrando grande perda óssea na região de maxila superior esquerda, de bordas difusas e irregulares (setas brancas) e área de radiotransparência na mandíbula, região de corpo e ramo da mandíbula, de bordas difusas (setas pretas). A imagem sugere processo maligno envolvendo maxila e mandíbula esquerdas.

\begin{abstract}
A ressonância magnética de pescoço demonstrou aumento de volume do lado esquerdo ocupando os espaços mastigatório, parotídeo, carotídeo, mucoso-faríngeo, sublingual e submandibular, com desvio das estruturas da linha média para a direita no espaço mastigatório, com redução de $50 \%$ do diâmetro da faringe. Envolvimento de corpo e
\end{abstract} ângulo da mandíbula do lado esquerdo. Envolvimento da artéria carótida interna e externa à esquerda. Linfonodomegalia submandibular esquerda. Foi sugerido pesquisa de sarcoma ou linfoma.

A paciente foi encaminhada ao hospital oncológico, quando foi submetida a biópsia de mucosa jugal, cujo diagnóstico foi de Linfoma não Hodgkin difuso, com necessidade de imunohistoquímica para classificação do mesmo (Figura 3).
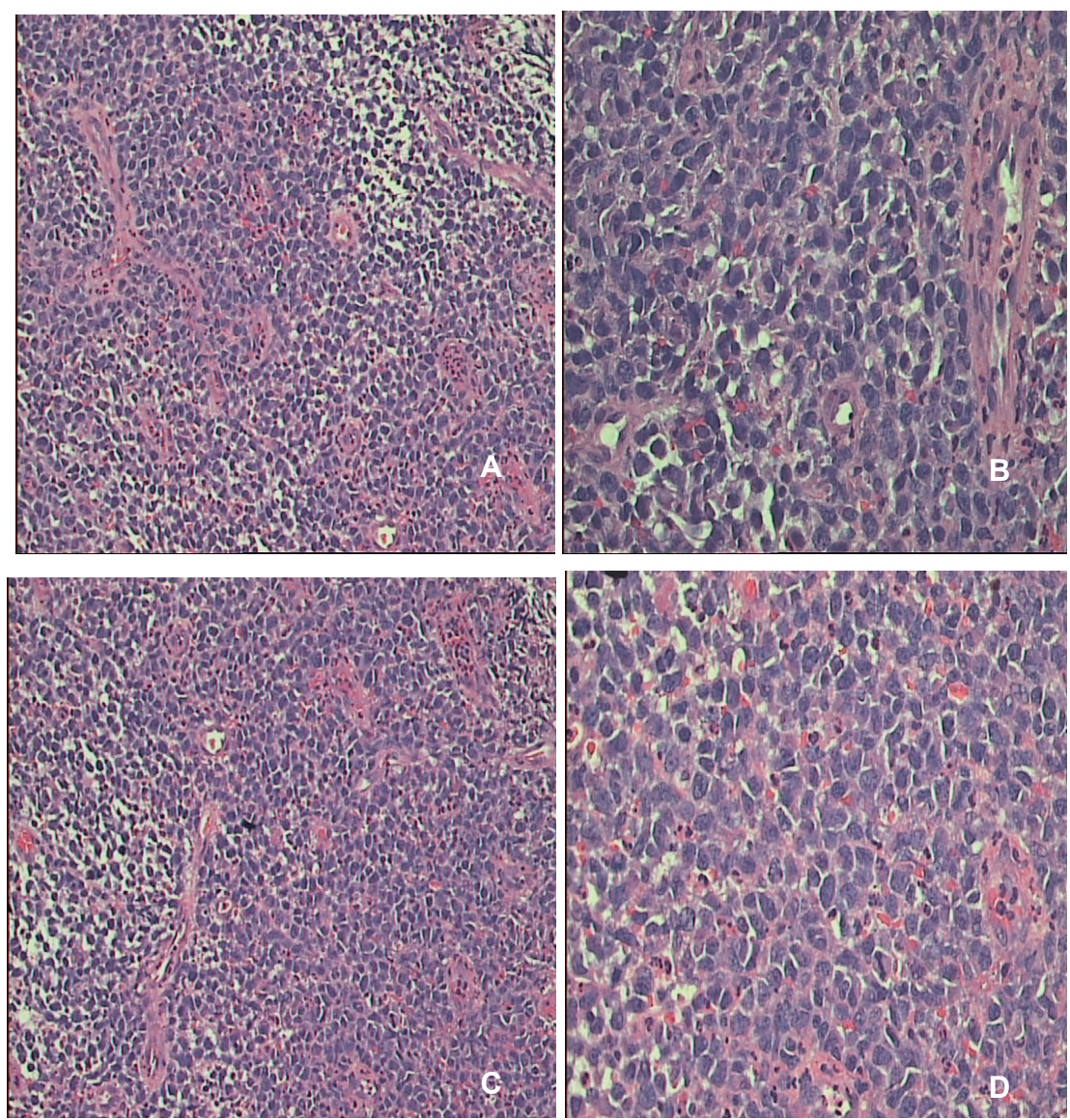

Figura 3 - Fotomicrografias: 3A e 3C - Intensa presença de linfócitos invadindo o tecido conjuntivo. HE - Aumento de 200 X. 3B e 3D - Linfócitos anaplásicos, exibindo forma e padrões de malignidade HE - Aumento de 400X. Compatível com Linfoma Maligno Não Hodgkin Difuso. 
Os cortes histológicos foram submetidos aos marcadores: CD-3, CD-20, Antígeno Ki67 e CD-30. O resultado foi positivo para CD20 e positivo alto para Ki-67.

As células neoplásicas não se coraram com o marcador de linfócitos T (CD-3) nem

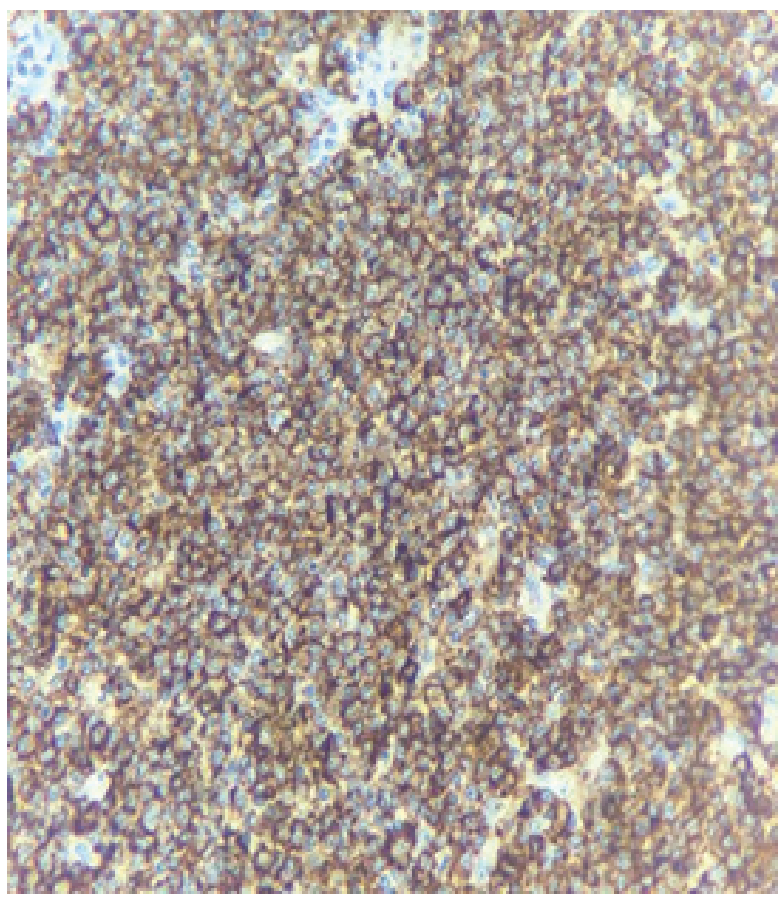

para CD-30, porém, difusamente para marcador de células $B, C D-20$. O índice de proliferação celular mensurado pelo Ki-67 consistiu em $80 \%$ de células neoplásicas. O diagnóstico foi de Linfoma difuso de grandes células e imunofenótipo B (Figura 4).

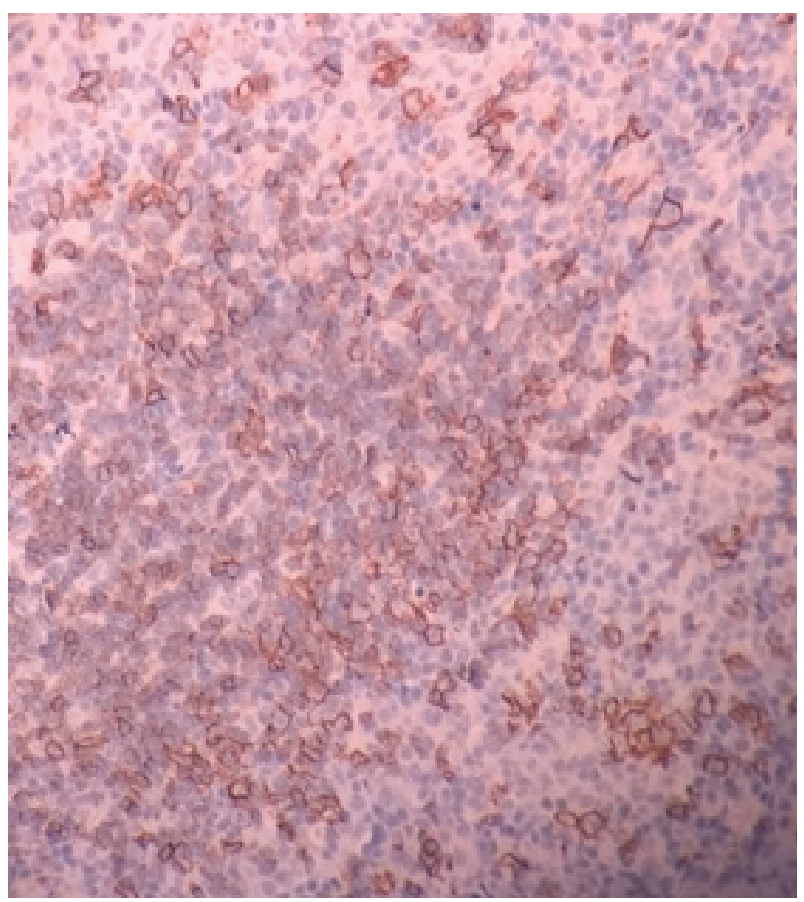

Figura 4 - Fotomicrografias- Imuno-histoquímica com positividade para CD-20, com imunofenótipo B.

Uma vez concluido o diagnóstico, a paciente foi submetida a oito sessões de quimioterapia, com remissão significante do quadro clínico e também a sessões de radioterapia. A mesma encontra-se em proservação pelo serviço de oncologia há um ano e meio, no setor de hematologia oncológica.

\section{DIscussão}

Os linfomas podem ser morfologicamente classificados em linfomas de Hodgkin e linfomas não Hodgkin. O linfoma difuso de grandes células $B$ se caracteriza como o subtipo mais comum entre os LNH, apresenta uma evolução relativamente rápida e não se limita apenas a órgãos linfáticos e linfonodos, podendo envol- ver também regiões extranodais..$^{8,9} \mathrm{Na}$ cavidade oral, o anel linfático de Waldeyer (nasofaringe, tonsilas palatinas, orofaringe e base da língua) constitui o local de maior incidência, seguido por mucosa oral, glândulas salivares, assoalho bucal, área retromolar e, com menor frequência, estruturas ósseas. ${ }^{10,11} \mathrm{O}$ acometimento é com frequência observado na sexta década de vida, por volta dos 66 anos, ${ }^{12}$ além disso, o sexo feminino apresenta taxa de incidência duas vezes maior que o masculino. ${ }^{5,12}$ Assim, a região retromolar, nasofaringe e tecido ósseo podem ser francamente comprometidos em mulheres por volta da faixa etária descrita.

Sudorese noturna, febre e perda de peso são sintomas sistêmicos rotineiramente associados ao linfoma difuso de grandes células 
B. ${ }^{5}$ Nos tecidos bucais e maxilofaciais as lesões podem se apresentar clinicamente como áreas edemaciadas, dolorosas ou assintomáticas, de rápida evolução, podendo provocar parestesia, mobilidade dentária e com frequência recobertas por mucosa ulcerada, ${ }^{5,2,13}$ sendo possível identificar, no exame intraoral, acometimento da maxila, palato, glândulas parótidas, mucosa oral, área retromolar, assoalho bucal e mandíbula, ${ }^{11,12,14}$ à semelhança da lesão observada no caso clínico. Porém, de maneira antagônica ao que foi identificado no caso proposto, pode haver ausência de linfoadenopatia. ${ }^{14} \mathrm{~A}$ análise de exame radiográfico muitas vezes identifica radiolucência com bordas difusas e irregulares, características encontradas em processos malignos ${ }^{5}$ como na radiografia panorâmica observada no caso desse linfoma, onde a radiolucidez invadia tecidos duros da mandíbula.

Apesar da etiologia do linfoma difuso de grandes células $\mathrm{B}$ ainda ser considerada incerta, ${ }^{4}$ há na literatura fatores discutidos como de risco, a exemplo de portadores do vírus da imunodeficiência humana (HIV), doenças autoimunes, exposição a agentes químicos deletérios, quimioterapia e radiação, ${ }^{11,15}$ o que não justifica os achados de hipertensão, nesse linfoma não Hodgkin, como um fator predisponente.

Os diagnósticos iniciais podem indicar cisto residual, abscesso agudo, fibroma, osteomielite aguda, granuloma piogênico, neuralgia trigeminal, cisto odontogênico, schwannoma intraósseo, lesão de células gigantes, mixoma, adenoma pleomórfico, osteossarcoma, carcinoma metastático, carcinoma espinocelular e linfoma. A hipótese diagnóstica inicial é transponível, complexa e pode ser heterogênea, fato encontrado no caso clínico, devido à ausência de achados histopatológicos e imuno-histoquímicos nas primeiras avaliações. ${ }^{7,8,9,10,14,16,17,18,19,20}$ A PAAF é relevante em casos onde o estado geral do paciente aumenta os riscos de procedimentos mais invasivos e se torna uma opção para identificar malignidade positiva. Entretanto, existe o risco da obtenção de material insuficiente para o diagnóstico, ${ }^{20}$ fato que não ocorreu no caso clínico proposto. É imprescindível a biópsia incisional seguida de análise histopatológica e imunoistoquímica para corroborar a malignidade e ratificar o diagnóstico de Linfoma Difuso de Grandes Células B, cuja identificação permite avaliar o prognóstico e tratamento. ${ }^{21,22}$

No caso citado, há um padrão histopatológico (coloração com hematoxilinaeosina) condizente com o LNH. Há presença considerável de células atípicas, com proliferação difusa de células linfoides com grandes núcleos hipercromáticos, predominância de centroblastos (múltiplos nucléolos cercados por membrana) e alto índice mitótico. 4,14,18 Os marcadores utilizados para determinar o tipo de células e padrão de distribuição são adequados: CD-20 (positivo) e Ki-67 (80\%, valor que expressa maior proliferação associada à diminuição da sobrevida) e foram imprescindíveis para o diagnóstico de Linfoma difuso de grandes células $B$, logo, mostraram negatividade para CD-3 (marcador de célula T) e CD30 (presente em alguns linfomas $B$ e outros linfomas $T$ polimórficos) que são antígenos inespecíficos para linfomas difusos B. ${ }^{12,14,21,23}$

No presente caso, adotou-se o tratamento com terapia clássica, com sessões de quimioterapia (oito ciclos) e radioterapia, exibindo remissão inicial considerável. ${ }^{9,16,17,20}$

\section{CONSIDERAÇõES FINAIS}

Conclui-se que é de suma importância a avaliação sistemática por parte do cirurgiãodentista devido à heterogeneidade clínica do linfoma difuso de grandes células $\mathrm{B}$ e a importância do diagnóstico precoce visa uma maior taxa de sobrevida do paciente. 


\section{REFERÊNCIAS}

1. Tinoco P., Pereira JCO, Ferreira FR, Carrara VL, Tinoco MBO. B-cell non-Hodgkin lymphoma of the ethmoid sinus. Braz J Otorhinolaryngol, 2013, 79 (2): 259. Disponível em: https://www. doi.org/10.5935/1808-8694.20130046. Acesso em: 10 mai. 2019.

2. Bray F., Ferlay J., Soerjomataram I., Siegel RLS, Torre LA, Jemail A. Global cancer statistics 2018: GLOBOCAN estimates of incidence and mortality worldwide for 36 cancers in 185 countries. CA Cancer J Clin, 2018, 68 (6): 394424. Disponível em: http://dx.doi.org/10.3322/ caac.21492. Acesso em: 24 out. 2019.

3. Instituto Nacional De Câncer. Linfoma não Hodgkin, 2018. Disponível em: https://www. inca.gov.br/tipos-de-cancer/linfoma-nao-hodgkin. Acesso em: 24 out. 2019.

4. Rodrigues-Fernandes Cl, Souza LL, Santos-Costa SF, Pontes HAR, Almeida OP, Vargas PA et al. Clinicopathological analysis of oral diffuse large B - cell lymphoma, NOS: A systematic review. J Oral Pathol Med, 2019, 48: 185-191. Disponível em: https://doi.org/10.1111/ jop.12802. Acesso em: 15 mai. 2019.

5. Bortoluzzi MC, Batista JD, Cherubini K., Salum FG, Figueiredo MA. Diffuse large B-cell lymphoma of the oral cavity. Revista Cubana de Estomatología, 2010, 47 (3): 341-346. Disponível em: http://www.revestomatologia.sld.cu/ index.php/est/article/viewFile/2676/1003. Acesso em: 15 mai. 2019.

6. Hu R., Winter A., Hill BT. The Emerging Role of Minimal Residual Disease Testing in Diffuse Large B-Cell Lymphoma. Current Oncology Reports, 2019, 21 (44). Disponível em: https:// doi.org/10.1007/s11912-019-0792-4. Acesso em: 13 abr. 2019.

7. Zhao H., Tang D., Zhu J., Zhang X., Tang Y., Li S. Diffuse Large B Cell Lymphoma Presented as Trigeminal Neuralgia: 2 Cases Reported and Literature Review. World Neurosurgery, 2019, 123: 383-389. Disponível em: https://doi. org/10.1016/j.wneu.2018.11.217. Acesso em: 4 mai. 2019.

8. Puneeth HK, Kumar SRR, Ananthaneni A., Jakkula NA. Physical torment: A predisposi- tion for diffuse B-cell lymphoma. J Oral Maxillofac Pathol, 2019, 23 (1): 17-22. Disponível em: https://www.ncbi.nlm.nih.gov/pmc/articles/ PMC6421932/\#_ffn_sectitle. Acesso em: 9 out. 2019.

9. Narang RS, Manchanda AS, Kaur H. Evaluation of a case of diffuse large B-cell lymphoma. J Oral Maxillofac Pathol, 2019, 23 (4): 7-11. Disponível em: http://www.jomfp.in/article. asp? issn $=0973-029 X ;$ year $=2019$; volume $=23$ ;issue $=4$; spage $=7$; epage $=11$; aulast $=$ Narang. Acesso em: 19 ago. 2019.

10. Fuessinger MA, Voss P., Metzger, MC, Zegpi C., Semper-Hogg W. Numb chin as signal for malignancy-primary intraosseous diffuse large B-Cell lymphoma of the mandible. Ann Maxillofac Surg, 2018, 8: 143-6. Disponível em: https://www.doi.org/10.4103/ams.ams_163_17. Acesso em: 9 out. 2019.

11. Zou H., Yang H., Zou H., Lei L., Song L. Primary diffuse large B-cell lymphoma in the maxila. Medicine, 2018, 97 (20). Disponível em: http:// dx.doi.org/10.1097/MD.0000000000010707. Acesso em: 19 ago. 2019.

12. Hussein MR. Non-Hodgkin's lymphoma of the oral cavity and maxillofacial region: a pathologist viewpoint. Expert Review of Hematology, 2018, 11 (9): 737-748. Disponível em: https:// doi.org/10.1080/17474086.2018.1506326. Acesso em: 8 out. 2019.

13. Bernardes Silva TD, Ferreira CBT, Leite GB, Menezes Pontes JR, Antunes HS. Oral manifestations of lymphoma: a systematic review. Ecancer, 2016, 10 (665). Disponível em: https://www.doi.org/10.3332/ecancer.2016.665. Acesso em: 13 out. 2019.

14. Donaduzzi LC, Reinheimer A., Ramires da Silva MA, Noronha L., Johann ACBR, Franco A. et al. Primary Diffuse Large B Cell Lymphoma Mimicking Hyperplastic Reactive Lesion (Lymphoma of the Oral Cavity). Case Reports in Pathology, 2018. Disponível em: https://doi. org/10.1155/2018/2981689. Acesso em: 13 out. 2019.

15. De Felice F., Di Mino A., Grapulin L., Mistrulli ML, Musio D., Trombolini V. Head and neck diffuse large $B$ cell lymphomas (HN-DLBCL) in human immunodeficiency virus (HIV) positive 
patients: long-term results in the highly active antiretroviral therapy. Eur Arch Otorhinolaryngol, 2017, 274: 3.735-3.739. Disponível em: https://www.doi.org/10.1007/s00405-017-4672-y. Acesso em: 9 out. 2019.

16. Kini R., Saha A., Naik V. Diffuse Large B-cell lymphoma of mandible: A case report. Med Oral Patol Oral Cir Bucal, 2009,14 (9): 4214. Disponível em: http://www.medicinaoral.com/ medoralfree01/v14i9/medoralv14i9p421.pdf. Acesso em: 13 out. 2019.

17. Bhattacharyya, I., Chehal HK, Cohen DM, Al-Quran SZ. Primary diffuse large B-cell lymphoma of the oral cavity: germinal center classification. Head and Neck Pathol, 2010, 4 (3): 181191. Disponível em: https://doi.org/10.1007/ s12105-010-0184-4. Acesso em: 13 out. 2019.

18. Okahata R., Shimamoto H., Marutani K., Tomita S., Nakatami A., Kishino M. et al. Diffuse large B-cell lymphoma of the mandible with periosteal reaction: a case report. Oral Surg Oral Med Oral Pathol Oral Radiol 2014, 117 (2): 228232. Disponível em: https://doi.org/10.1016/j. oooo.2013.12.002. Acesso em: 13 out. 2019.

19. Bugshan A., Kassolis J., Basile J. Primary Diffuse Large B-Cell Lymphoma of the Mandible: Case Report and Review of the Literature. Case Rep Oncol, 2015, 8: 451-455. Disponível em: https://doi.org/10.1159/000441469. Acesso em: 13 out. 2019.

20.Sahoo SR, Misra SR, Mishra L., Mishra S. Primary diffuse large B-cell ymphoma in the anterior hard palate: A rare case report with review ofliterature. J Oral Maxillofac Pathol, 2014, 18 (1): 102-106. Disponível em: https://www. ncbi.nlm.nih.gov/pmc/articles/PMC4065424/. Acesso em: 13 out. 2019.

21. Leval L., Harris NL. Variability in immunophenotype in diffuse large B-cell lymphoma and its clinical relevance. Histopathology, 2003, 43 (6): 509-528. Disponível em: https://doi. org/10.1111/j.1365-2559.2003.01758.x. Acesso em: 13 out. 2019.

22. Siqueira JM, Fernandes PM, Ferraz de Oliveira AC, Alves FA, Jaguar GC. Primary diffuse large B-cell lymphoma of the mandible. Autops Case Rep, 2019, 9 (3). Disponível em: https://doi. org/10.4322/acr.2019.109. Acesso em: 13 out. 2019.

23. Shi Y., Han Y., Yang J., Liu P., He X., Zhang C. et al. Clinical features and outcomes of diffuse large B-cell lymphoma based on nodal or extranodal primary sites of origin: Analysis of 1,085 WHO classified cases in a single institution in China. Chin J Cancer Res, 2019, 31 (1): 152161. Disponível em: https://doi.org/10.21147/j. issn.1000-9604.2019.01.10. Acesso em: 19 ago. 2019.

Submetido em: 13-8-2020

Aceito em: 28-09-2020 